ARTICLE

\title{
Faradaic junction and isoenergetic charge transfer mechanism on semiconductor/semiconductor interfaces
}

Mingzhi Chen 1,3, Hongzheng Dong ${ }^{1,3}$, Mengfan Xue ${ }^{2,3}$, Chunsheng Yang ${ }^{1}$, Pin Wang ${ }^{2}$, Yanliang Yang ${ }^{1}$ Heng Zhu', Congping Wu ${ }^{2}$, Yingfang Yao ${ }^{1}$, Wenjun Luo (i) ${ }^{1 \times} \&$ Zhigang Zou (D) ${ }^{1,2}$

Energy band alignment theory has been widely used to understand interface charge transfer in semiconductor/semiconductor heterojunctions for solar conversion or storage, such as quantum-dot sensitized solar cells, perovskite solar cells and photo(electro)catalysis. However, abnormally high open-circuit voltage and charge separation efficiency in these applications cannot be explained by the classic theory. Here, we demonstrate a Faradaic junction theory with isoenergetic charge transfer at semiconductor/semiconductor interface. Such Faradaic junction involves coupled electron and ion transfer, which is substantively different from the classic band alignment theory only involving electron transfer. The Faradaic junction theory can be used to explain these abnormal results in previous studies. Moreover, the characteristic of zero energy loss of charge transfer in a Faradaic junction also can provide a possibility to design a solar conversion device with a large open-circuit voltage beyond the Shockley-Queisser limit by the band alignment theory.

\footnotetext{
${ }^{1}$ Eco-materials and Renewable Energy Research Center (ERERC), National Laboratory of Solid State Microstructures, College of Engineering and Applied Sciences, Nanjing University, Nanjing 210093, China. ${ }^{2}$ Eco-materials and Renewable Energy Research Center (ERERC), Jiangsu Key Laboratory for Nano Technology, National Laboratory of Solid State Microstructures and Department of Physics, Nanjing University, Nanjing 210093, China. ${ }^{3}$ These authors

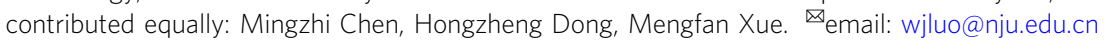


S ince an energy band-alignment theory on $\mathrm{p}-\mathrm{n}$ junctions was first proposed in $1949^{1}$ (Supplementary Fig. 1), a Si solar cell was developed to convert solar energy to electricity ${ }^{2}$. According to the band-alignment theory, Shockley and Queisser proposed a method to calculate the efficiency limit of a $\mathrm{p}-\mathrm{n}$ solar cell, which has been a guideline in this field ${ }^{3}$. Thereafter, several emerging low-cost semiconductor/semiconductor junctions, such as quantum-dot-sensitized solar cells ${ }^{4-6}$ and perovskite solar cells ${ }^{7-10}$, have been widely used for solar conversion. The bandalignment theory has also been used to calculate theoretical photovoltages of these emerging solar cells. For instance, a theoretical open-circuit voltage $\left(\mathrm{V}_{\mathrm{OC}}\right)$ in a quantum-dot-sensitized solar cell (Supplementary Fig. 2a) can be obtained from the difference between the conduction-band position of electrontransporting layer and redox potential ${ }^{6}$. Out of the expectation, some recent studies suggest that the experimental value of $\mathrm{V}_{\mathrm{OC}}$ is higher than the theoretical value in a quantum-dot-sensitized solar cell. Moreover, the $\mathrm{V}_{\mathrm{OC}}$ value changes with altering a quantum-dot sensitizer, but keeps constant with altering an electron-transporting material. These results are evidently inconsistent with the classic band-alignment theory ${ }^{11,12}$. Similar phenomena have also been observed in perovskite solar cells, in which the $V_{\text {OC }}$ value is only dependent on the band position of a perovskite absorber and a hole-transporting layer, not on an electron-transporting layer (Supplementary Fig. 2b) ${ }^{10}$. Such abnormal $\mathrm{V}_{\mathrm{OC}}$ of a quantum-dot-sensitized or perovskite solar cell does not follow the classic band-alignment theory, which is still unclear to date.

Moreover, semiconductor/semiconductor heterojunctions have been widely used to improve photocatalytic ${ }^{13-17}$ or photoelectrocatalytic $^{18-20}$ performance. Two kinds of different interface charge-transfer mechanisms based on energy band alignment theory, type-II (Supplementary Fig. 2c) and direct Z-scheme heterojunction (Supplementary Fig. 2d), have been proposed to explain improved solar-conversion efficiency. In a type-II heterojunction, charge separation efficiency and photocurrent are enhanced significantly, which is mainly due to the built-in electric field at the interface. It is worthy to note that the charge separation in type-II heterojunction would decrease both reduction potential of electrons and oxidation potential of holes after interface charge transfer, and thereby leads to obvious photovoltage loss. However, some recent studies suggest that no energy loss of electrons is observed after interface charge transfer ${ }^{17,21}$. Therefore, a direct Z-scheme heterojunction mechanism was proposed to explain this phenomenon. For example, in a $\mathrm{TiO}_{2} / \mathrm{CdS}$ direct Z-scheme heterojunction, the electrons in the conduction band of $\mathrm{TiO}_{2}$ would recombine with the holes in the valence band of CdS, while the holes in $\mathrm{TiO}_{2}$ and the electrons in CdS can thus maintain their high oxidization and reduction potentials, respectively. However, no electrons could be photoexcited in $\mathrm{TiO}_{2}$ under visible-light irradiation, which would result in less enhancement in the performance of a $\mathrm{TiO}_{2} / \mathrm{CdS}$ heterojunction. Nevertheless, remarkable enhancement on the photocatalytic performance of $\mathrm{TiO}_{2} / \mathrm{CdS} \mathrm{Z}$-scheme heterojunction was observed under both the full-arc and visible-light illumination ${ }^{22}$. The inconsistent results aforementioned suggest that the classic band-alignment theory is not suitable to describe this abnormal high $\mathrm{V}_{\mathrm{OC}}$ and charge-separation efficiency. Therefore, it is highly desirable to propose a theory to comprehend the interface charge transfer in these semiconductor/semiconductor junctions.

Herein, by using a $\mathrm{TiO}_{2} / \mathrm{CdS}$ junction as a model, we investigated interface charge-transfer mechanism by in situ XPS, (quasi) in situ UV-vis, (quasi) in situ Raman, and electrochemicalimpedance spectroscopy (EIS). Accordingly, we find that a $\mathrm{TiO}_{2} /$ CdS heterojunction is a Faradaic junction, which is totally different from classic type-II or Z-scheme heterojunction. When photogenerated electrons in the conduction band of CdS inject into $\mathrm{TiO}_{2}$ with $\mathrm{H}^{+}$ions from electrolyte, an intrinsic Faradaic layer on the surface of $\mathrm{TiO}_{2}$ is reduced. The fast Faradaic reaction leads to much higher charge-separation efficiency in the $\mathrm{TiO}_{2} / \mathrm{CdS}$ Faradaic junction. The semiconductor/semiconductor Faradaic junction is also different from a semiconductor/farador junction in previous studies and few people consider a semiconductor as a farador with redox characteristic ${ }^{23,24}$. Very importantly, we also find the characteristic of isoenergetic interfacial charge transfer in the $\mathrm{TiO}_{2} / \mathrm{CdS}$ Faradaic junction, which can keep high reduction potential of the electrons in the semiconductor with higher conduction band. The Faradaic junction theory on semiconductor/ semiconductor interface can be used to explain all these inconsistent results aforementioned in solar cells and photo(electro) catalysis fields. The theory is different from the classic bandalignment theory that was proposed over 70 years ago, which also provides a possibility to design a solar-conversion or storage device with a high $\mathrm{V}_{\mathrm{OC}}$ even beyond the Shockley-Queisser limit.

\section{Results}

Characterization and photoelectrochemical performance of $\mathrm{TiO}_{2} /$ CdS. A $\mathrm{TiO}_{2} / \mathrm{CdS}$ heterojunction was deposited on a FTO substrate by hydrothermal and successive ionic-layer adsorption and reaction method. Single $\mathrm{TiO}_{2}$ and CdS electrode were also prepared as reference samples. Supplementary Fig. 3 and Fig. 1a indicate the scanning electron microscope (SEM) and transmission electron microscope (TEM) images of a $\mathrm{TiO}_{2} / \mathrm{CdS}$ heterojunction. CdS particles are uniformly coated on $\mathrm{TiO}_{2}$ singlecrystal nanorod arrays. The lattice spacing of $0.32 \mathrm{~nm}$ and $0.29 \mathrm{~nm}$ corresponds to the (110) and (001) of rutile $\mathrm{TiO}_{2}$, respectively. The observed $0.337-\mathrm{nm}$ fringes on the surface of $\mathrm{TiO}_{2}$ nanorod correspond to the (111) of CdS. Figure $1 \mathrm{~b}$ and Supplementary Fig. 4 indicate the X-ray photoelectron spectroscopy (XPS) patterns of $\mathrm{TiO}_{2} / \mathrm{CdS}$. The binding energies of $\mathrm{Ti}^{4+}$, $\mathrm{Cd}^{2+}$, and $\mathrm{S}^{2-}$ peaks are observed on the surface of the sample, respectively. Similar to previous studies, the binding energies $(529.2 \mathrm{eV}, 530.9 \mathrm{eV}$, and $532.1 \mathrm{eV})$ of $\mathrm{O} 1 \mathrm{~s}$ are observed and assigned to the lattice $\mathrm{O}^{2-}$, lattice $\mathrm{OH}^{-}$, and adsorbed $\mathrm{H}_{2} \mathrm{O}$ molecules, which suggests that there is indeed a $\mathrm{TiO}_{2-\mathrm{x}}(\mathrm{OH})_{2 \mathrm{x}}$ layer on the surface of $\mathrm{TiO}_{2}{ }^{25}$.

In order to investigate the relationship between the $\mathrm{V}_{\mathrm{OC}}$ of a solar cell and band alignment of different materials, the flat band potentials of $\mathrm{TiO}_{2}$ and CdS were measured by Mott-Schottky (M-S) method and the results are $0.05 \mathrm{~V}_{\mathrm{RHE}}$ and $-0.36 \mathrm{~V}_{\mathrm{RHE}}$ (Fig. 1c). Generally, the conduction-band position is about $0.05 \mathrm{~V}$ higher than the flat-band potential ${ }^{26}$. Therefore, the conductionband positions of $\mathrm{TiO}_{2}$ and $\mathrm{CdS}$ are $0 \mathrm{~V}_{\mathrm{RHE}}$ and $-0.41 \mathrm{~V}_{\mathrm{RHE}}$, respectively, which are in good agreement with previous reports ${ }^{27,28}$. Similar band positions of $\mathrm{TiO}_{2}$ and $\mathrm{CdS}$ are also obtained by ultraviolet photoelectron spectroscopy and UV-visible absorption spectroscopy methods (Supplementary Fig. 5 and Table 1). Moreover, the redox potential of $S^{2-} / S$ was also measured as $0.41 \mathrm{~V}_{\mathrm{RHE}}$ on a Pt/FTO electrode by cyclic voltammetry (CV) method (Supplementary Fig. 6). According to the results, the band positions of $\mathrm{CdS}, \mathrm{TiO}_{2}$, and redox potential of $\mathrm{S}^{2-} / \mathrm{S}$ are plotted in Fig. 1d. From a classic band-alignment theory, a maximum theoretical $\mathrm{V}_{\mathrm{OC}}$ of a $\mathrm{CdS}$ quantum-dotsensitized solar cell is $0.41 \mathrm{~V}$. In order to investigate the experimental $\mathrm{V}_{\mathrm{OC}}$, a solar cell was assembled with a $\mathrm{TiO}_{2} / \mathrm{CdS}$ heterojunction as a photoanode, a Pt/FTO as a counter electrode, and polysulfide solution as electrolyte (Fig. 1e). The I-V curves of the solar cell were measured under illumination and in the dark, as shown in Fig. 1f. $A V_{O C}$ of $0.55 \mathrm{~V}$ is obtained from the $\mathrm{I}-\mathrm{V}$ curve, which is further confirmed by open-circuit potential 
method (Supplementary Fig. 7). The experimental $\mathrm{V}_{\mathrm{OC}}$ is close to previously reported values ${ }^{29}$ and is higher than the theoretical value of $0.41 \mathrm{~V}$. The $\mathrm{V}_{\mathrm{OC}}$ of a quantum-dot-sensitized solar cell cannot be explained by classic band-alignment theory.

Experimental evidence on a Faradaic reaction at $\mathrm{TiO}_{2} / \mathrm{CdS}$ interface. In order to clarify the reasons for abnormally high $\mathrm{V}_{\mathrm{OC}}$, we investigated interface charge-transfer mechanism in $\mathrm{TiO}_{2} / \mathrm{CdS}$ by in situ XPS, (quasi) in situ UV-vis, (quasi) in situ Raman, and EIS method. In the dark, only $\mathrm{Ti}^{4+}$ is observed on the surface of $\mathrm{TiO}_{2} / \mathrm{CdS}$, while some $\mathrm{Ti}^{4+}$ is reduced into $\mathrm{Ti}^{3+}$ under illumination (Fig. 2a). The decrease of the ratio of lattice $\mathrm{OH}^{-}$/lattice $\mathrm{O}^{2-}$ under illumination comes from oxidation of $\mathrm{OH}^{-}$by photogenerated holes in $\mathrm{TiO}_{2}$ (Fig. 2b). Moreover, the binding energies of $\mathrm{Cd} 3 \mathrm{~d}$ and $\mathrm{S} 2 \mathrm{p}$ do not change under illumination (Supplementary Fig. 8), which suggests that a chemical reaction only happens on the surface of $\mathrm{TiO}_{2}$ rather than $\mathrm{CdS}$. In order to further investigate the reaction on the surface of $\mathrm{TiO}_{2} / \mathrm{CdS}$, quasi in situ UV-vis reflectance spectra of a $\mathrm{TiO}_{2} / \mathrm{CdS}$ heterojunction were measured under open-circuit condition before and after fullarc Xe lamp illumination and the results are shown in Fig. 2c. After illumination, $\mathrm{TiO}_{2} / \mathrm{CdS}$ indicate lower reflectance at the wavelength range of $520-800 \mathrm{~nm}$. In contrast, reflectance spectra of a single $\mathrm{CdS}$ and $\mathrm{TiO}_{2}$ electrode do not change after illumination (Supplementary Fig. 9). Moreover, a PL peak of CdS at $690 \mathrm{~nm}^{30}$ is quenched by contacting with $\mathrm{TiO}_{2}$ (Supplementary Fig. 10), which suggests that interface charge transfer happens between $\mathrm{CdS}$ and $\mathrm{TiO}_{2}$. The lower reflectance after illumination possibly comes from charge-transfer-induced change of $\mathrm{TiO}_{2} /$ CdS. The same change trend of reflectance spectra was also observed when the $\mathrm{TiO}_{2} / \mathrm{CdS}$ was illuminated under visible light $(\lambda>450 \mathrm{~nm})$, though $\mathrm{TiO}_{2}$ was not excited (Fig. 2d). Therefore, the visible light can still lead to the change of $\mathrm{TiO}_{2} / \mathrm{CdS}$. In order to identify the change of reflectance from $\mathrm{TiO}_{2}$ or CdS, we measured in situ reflectance spectra of a single $\mathrm{CdS}$ and $\mathrm{TiO}_{2}$ electrode at different potentials in the dark (Fig. 2e, f). The reflectance spectra of a CdS electrode do not change at the potential range from $-0.4 \mathrm{~V}_{\mathrm{RHE}}$ to $0.1 \mathrm{~V}_{\mathrm{RHE}}$, while the reflectance spectra of $\mathrm{a} \mathrm{TiO}_{2}$ electrode decrease at the potentials negative than $-0.2 \mathrm{~V}_{\mathrm{RHE}}$, which comes from a reduction reaction of an intrinsic Faradaic layer of $\mathrm{TiO}_{2-\mathrm{x}}(\mathrm{OH})_{2 \mathrm{x}}\left(\mathrm{Ti}^{+4} \mathrm{O}_{2-\mathrm{x}}(\mathrm{OH})_{2 \mathrm{x}}+\right.$ $\left.\mathrm{H}^{+}+\mathrm{e}^{-} \leftrightarrow \mathrm{Ti}^{+3} \mathrm{O}_{1-\mathrm{x}}(\mathrm{OH})_{2 \mathrm{x}+1}\right)$ on the surface of $\mathrm{TiO}_{2}{ }^{31}$. The electron concentration in the surface Faradaic layer of $\mathrm{TiO}_{2}$ increases remarkably after reduction and leads to plasmaresonance absorption of free electrons at long wavelength ${ }^{32}$. Therefore, the lower reflectance in $\mathrm{TiO}_{2} / \mathrm{CdS}$ after illumination suggests that a reduction Faradaic reaction happens on the surface of $\mathrm{TiO}_{2}$.

In order to make clear why the Faradaic reaction happens only on the surface of $\mathrm{TiO}_{2}$, not CdS, CV and galvanostatic charge-discharge (GCD) curves of $\mathrm{TiO}_{2}$ and $\mathrm{CdS}$ were measured and the results are shown in Supplementary Fig. 11. Obvious hysteresis loop of a Faradaic reaction is observed in the CV curve of $\mathrm{TiO}_{2}$ but not in CdS (Supplementary Fig. 11a). The Faradaic potential window of $\mathrm{TiO}_{2-\mathrm{x}}(\mathrm{OH})_{2 \mathrm{x}}$ is further determined at the potential range from $-0.4 \mathrm{~V}_{\mathrm{RHE}}$ to $0.1 \mathrm{~V}_{\mathrm{RHE}}$ by GCD method, while negligible Faradaic charge and discharge process is observed on CdS (Supplementary Fig. 11b). The results are in good agreement with previous study ${ }^{31}$. Therefore, a Faradaic reaction happens more easily on $\mathrm{TiO}_{2}$ than on $\mathrm{CdS}$ at the same reduction potential.

Quasi in situ Raman spectroscopy was also used to investigate interface changes ${ }^{33}$ in a $\mathrm{TiO}_{2} / \mathrm{CdS}$ heterojunction under illumination and the results are shown in Fig. 3a. The Raman peak intensity of $\mathrm{TiO}_{2} / \mathrm{CdS}$ decreases after illumination, which comes from the formation of amorphous $\mathrm{Ti}^{+3} \mathrm{O}_{1-\mathrm{x}}(\mathrm{OH})_{2 \mathrm{x}+1}$ on the surface of $\mathrm{TiO}_{2}{ }^{34}$. In contrast, the Raman peak intensities of single $\mathrm{CdS}$ and $\mathrm{TiO}_{2}$ do not change after illumination, which further confirm the interface charge transfer in $\mathrm{TiO}_{2} / \mathrm{CdS}$ (Supplementary Fig. 12). Similar to in situ UV-vis
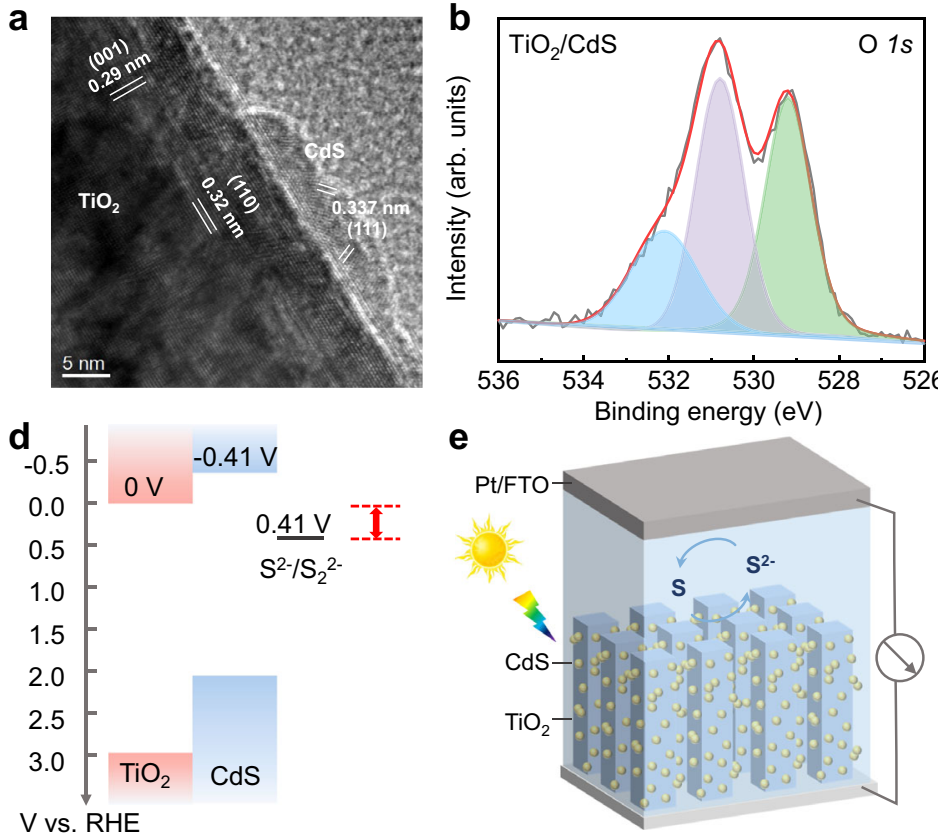

e

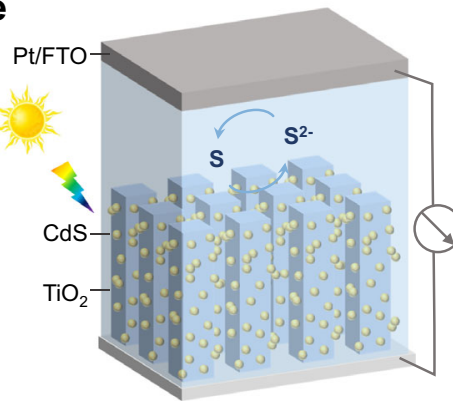

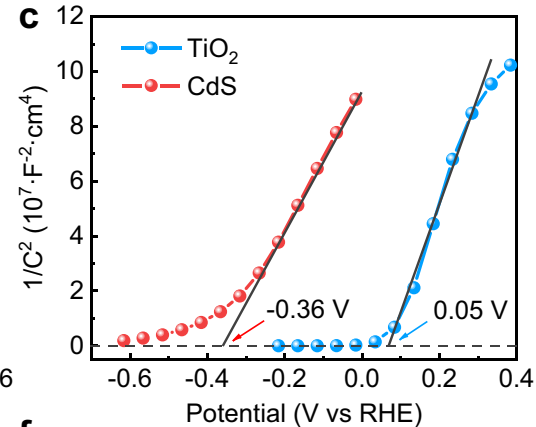

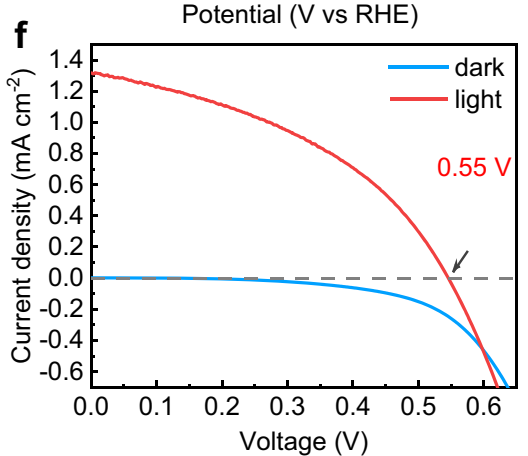

Fig. 1 Characterization and $\mathbf{V}_{\mathbf{~ o c}}$ of $\mathbf{T i O}_{2} / \mathbf{C d S}$. a A TEM image of $\mathrm{TiO}_{2} / \mathrm{CdS}$, (b) XPS spectra of $\mathrm{O} 1 \mathrm{~s}$ of $\mathrm{TiO}_{2} / \mathrm{CdS}$, (c) Mott-Schottky plots of TiO 2 and CdS in $1 \mathrm{M} \mathrm{Na}_{2} \mathrm{~S}$ aqueous solution, (d) band positions of a $\mathrm{TiO}_{2} / \mathrm{CdS}$ heterojunction and redox potential of $\mathrm{S}^{2-} / \mathrm{S}$, (e) a schematic diagram of a TiO $2 / \mathrm{CdS}$ quantum-dot-sensitized solar cell, and (f) $\mathrm{I}-\mathrm{V}$ curves of $\mathrm{TiO}_{2} / \mathrm{CdS}$ quantum-dot-sensitized solar cells under illumination and in the dark. Electrolyte: $0.5 \mathrm{M} \mathrm{Na}_{2} \mathrm{~S}, 2 \mathrm{M} \mathrm{S}$, and $0.2 \mathrm{M} \mathrm{KCl}$ in water/methanol (3:7 by volume). Light source: a Xe lamp with an AM 1.5 sunlight-simulator filter, light intensity: $100 \mathrm{~mW} / \mathrm{cm}^{2}$. 

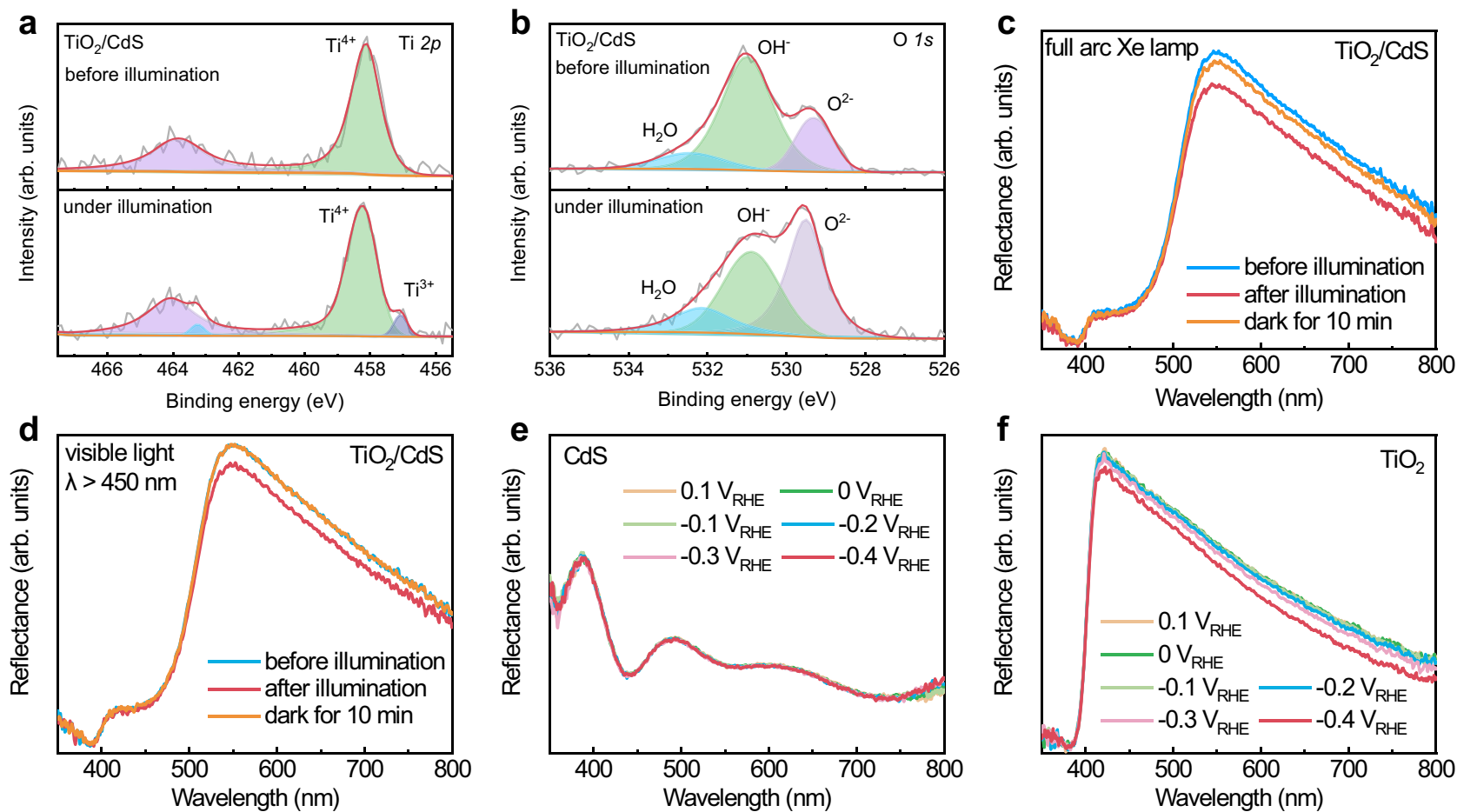

Fig. 2 Charge-transfer process at $\mathrm{TiO}_{2} / \mathbf{C d S}$ interface. In situ XPS spectra of $\mathrm{Ti} 2 \mathrm{p}(\mathbf{a})$ and $\mathrm{O} 1 \mathrm{~s}(\mathbf{b})$ in $\mathrm{TiO}_{2} / \mathrm{CdS}$ in the dark and under full arc Xe lamp illumination, quasi in situ UV-vis reflectance spectra of $\mathrm{TiO}_{2} / \mathrm{CdS}$ in $1 \mathrm{M} \mathrm{Na}_{2} \mathrm{~S}$ aqueous solution before and after illumination under full-arc Xe lamp (c) and visible light of $\lambda>450 \mathrm{~nm}$ (d), and in situ UV-vis reflectance spectra of $\mathrm{CdS}(\mathbf{e})$ and $\mathrm{TiO}_{2}$ (f) in $1 \mathrm{M} \mathrm{Na}_{2} \mathrm{~S}$ aqueous solution at different potentials in the dark.
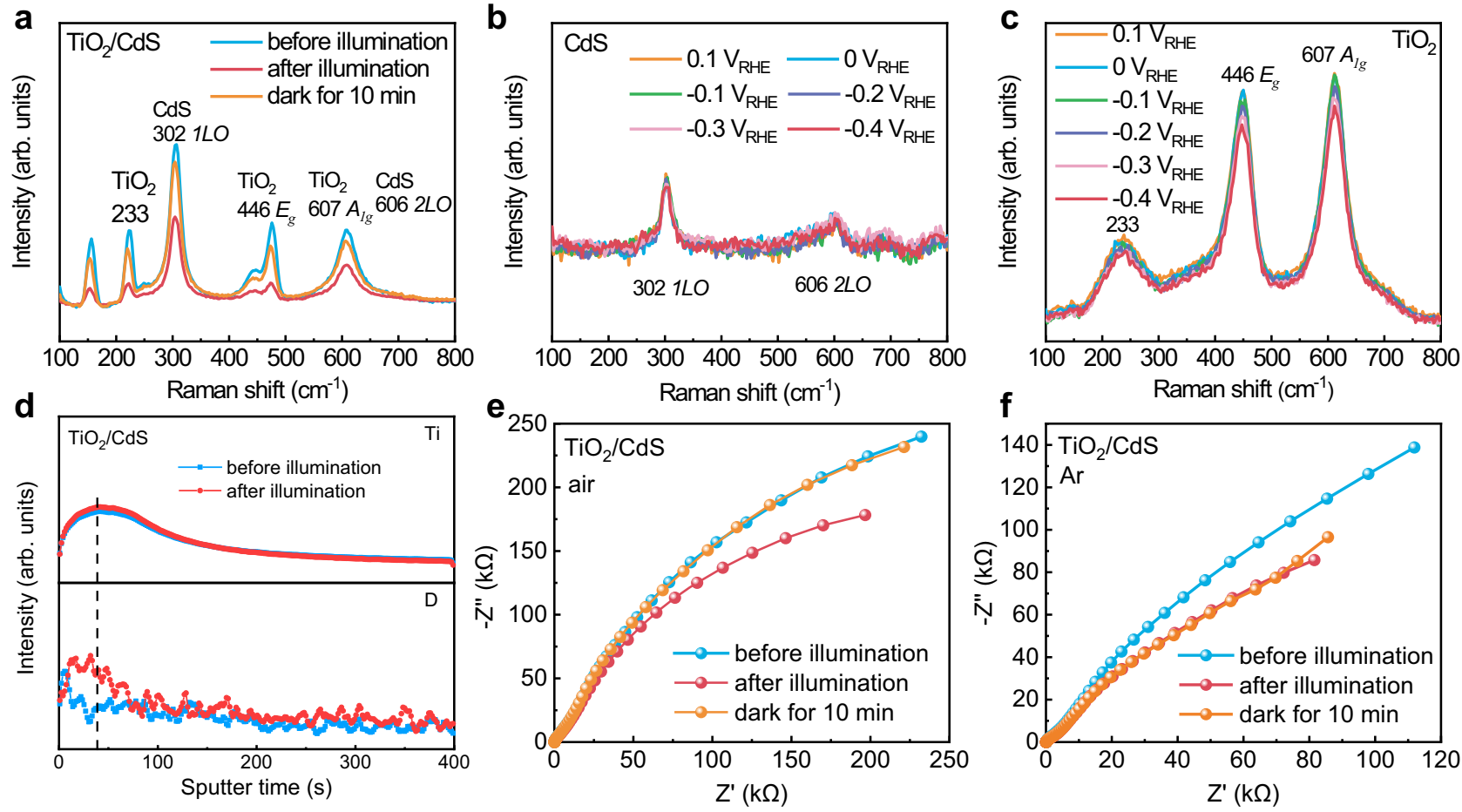

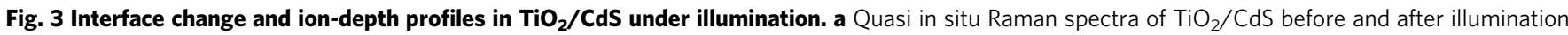
under full-arc Xe lamp, in situ Raman spectra of $\mathrm{CdS}(\mathbf{b})$ and $\mathrm{TiO}_{2}$ (c) in $1 \mathrm{M} \mathrm{Na}_{2} \mathrm{~S}$ aqueous solution at different potentials in the dark, (d) secondary ion intensities of $\mathrm{Ti}$ and $\mathrm{D}$ ions in a $\mathrm{TiO}_{2} / \mathrm{CdS}$ junction in the electrolyte $\left(1 \mathrm{M} \mathrm{Na}_{2} \mathrm{~S}\right.$ in $\mathrm{D}_{2} \mathrm{O}$ solution) before and after illumination for 10 min, electrochemicalimpedance spectroscopy @0.4 $\mathrm{V}_{\mathrm{RHE}}$ of $\mathrm{TiO}_{2} / \mathrm{CdS}$ in $1 \mathrm{M} \mathrm{Na}_{2} \mathrm{~S}$ aqueous solution with air (e) and with $\mathrm{Ar}(\mathbf{f})$ before and after illumination under full-arc Xe lamp. 
characterization in Fig. $2 \mathrm{~b}$ and $\mathrm{c}$, in situ Raman spectra of CdS and $\mathrm{TiO}_{2}$ were also measured at different potentials in the dark. The Raman peak intensity of CdS changes slightly (Fig. 3b), but the Raman peak intensity of $\mathrm{TiO}_{2}$ decreases with decreasing potentials (Fig. 3c). Therefore, the Raman spectra also suggest that charge transfer induced surface changes not on CdS but on $\mathrm{TiO}_{2}$ under illumination. Moreover, no obvious XRD change is observed in $\mathrm{TiO}_{2} / \mathrm{CdS}$ before and after illumination (Supplementary Fig. 13), which further confirms that the Faradaic reaction only happens on the surface of $\mathrm{TiO}_{2}$, not the bulk. In order to investigate the reaction process of $\mathrm{H}$ ions in the intrinsic Faradaic layer, isotope-labeling experiments by using $\mathrm{D}_{2} \mathrm{O}$ as a solvent were carried out and time-of-flight secondary-ion mass spectrometry (TOF-SIMS) was used to analyze depth profiles of D ions in the Faradaic junction before and after illumination. The results are shown in Fig. $3 \mathrm{~d}$. Ti ions are observed at the depth with sputtering time of $0-100 \mathrm{~s}$ and the distribution does not change before and after illumination. For D-ion depth profile, only possible adsorption of $\mathrm{D}$ ions on the surface of the sample before illumination, no D ions can be observed at the depth with sputtering time $>10 \mathrm{~s}$. After illumination, remarkably enhanced intensity of D ions is observed, and the distribution is in good agreement with the $\mathrm{Ti}$ ions, which suggest that $\mathrm{D}$ ions in the electrolyte insert into $\mathrm{TiO}_{2}$ under illumination. The concentration of $\mathrm{H}$ ions has significant effects on the efficiency of the $\mathrm{TiO}_{2} / \mathrm{CdS}$ heterojunction (Supplementary Fig. 14), which further supports the Faradaic junction mechanism at $\mathrm{TiO}_{2} / \mathrm{CdS}$ interface. Moreover, we find that the Faradaic reaction at $\mathrm{TiO}_{2} / \mathrm{CdS}$ interface not only happens in liquid phase, but also in gas-phase and solidphase surroundings (Supplementary Figs. 15 and 16). Therefore, the Faradaic junction mechanism is universal to understand interface charge transfer in liquid photoelectrochemistry, gas photocatalysis, or solid-state solar cells.

Electrochemical-impedance spectroscopy (EIS) method was also used to investigate interface charge transfer in $\mathrm{TiO}_{2} / \mathrm{CdS}$ and the results are shown in Fig. 3e. In the dark, a $\mathrm{TiO}_{2} / \mathrm{CdS}$ heterojunction indicates similar EIS spectra with single $\mathrm{TiO}_{2}$, not CdS (Supplementary Fig. 17). Since CdS particles do not cover
$\mathrm{TiO}_{2}$ nanorods completely and $\mathrm{TiO}_{2}$ contacts with electrolyte directly, the impedance spectra of $\mathrm{TiO}_{2} / \mathrm{CdS}$ mainly reflect the property of $\mathrm{TiO}_{2}$. The semicircle at low frequency of $\mathrm{TiO}_{2} / \mathrm{CdS}$ decreases obviously after illumination, which comes from the lower charge-transfer resistance in the $\mathrm{TiO}_{2} /$ electrolyte interface ${ }^{35}$. In contrast, the impedance circle of single $\mathrm{TiO}_{2}$ and CdS does not change after the same illumination (Supplementary Fig. 18). Therefore, the decreased impedance semicircle of $\mathrm{TiO}_{2} /$ CdS after illumination comes from the reduction reaction of an intrinsic Faradaic layer of $\mathrm{TiO}_{2-\mathrm{x}}(\mathrm{OH})_{2 \mathrm{x}}$ by photogenerated electrons from $\mathrm{CdS}$. Moreover, since a Faradaic reaction is reversible, we also observed recovery process of UV-vis (Fig. 2c-d), Raman spectra (Fig. 3a) and EIS spectra (Fig. 3e) of $\mathrm{TiO}_{2} / \mathrm{CdS}$ when light was off and the sample was kept in electrolyte with air for $10 \mathrm{~min}$. In contrast, no recovery process of EIS spectra was observed in the same electrolyte with Ar bubbling (Fig. 3f). The results suggest that the reduced intrinsic Faradaic layer on the surface of $\mathrm{TiO}_{2}$ can be reoxidized by dissolved oxygen in the electrolyte.

A proposed mechanism. Subsequently, we further study interface charge transfer characteristics of $\mathrm{TiO}_{2} / \mathrm{CdS}$ Faradaic junction by linear-sweep voltammetry (LSV) and open-circuit potential (OCP) electrochemical methods. Figure $4 \mathrm{a}$ and b shows LSV curves of $\mathrm{TiO}_{2}, \mathrm{CdS}$ and $\mathrm{TiO}_{2} / \mathrm{CdS}$ in $1 \mathrm{M} \mathrm{Na}_{2} \mathrm{~S}$ aqueous solution under full-arc and visible-light illumination, respectively. The photocurrent-onset potentials of $\mathrm{TiO}_{2}, \mathrm{CdS}$, and $\mathrm{TiO}_{2} / \mathrm{CdS}$ are 0 $\mathrm{V}_{\mathrm{RHE}},-0.41 \mathrm{~V}_{\mathrm{RHE}}$ (Supplementary Fig. 19), and $-0.41 \mathrm{~V}_{\mathrm{RHE}}$, respectively, which are in good agreement with the conductionband position in Fig. 1d. The onset potential of $\mathrm{TiO}_{2} / \mathrm{CdS}$ is the same to that of $\mathrm{CdS}$, not $\mathrm{TiO}_{2}$, which suggests that the photogenerated electrons in CdS can be transferred to $\mathrm{TiO}_{2}$ without energy loss. Moreover, the $\mathrm{TiO}_{2} / \mathrm{CdS}$ indicates much higher stable photocurrent than those of $\mathrm{TiO}_{2}$ and $\mathrm{CdS}$ at different potentials, especially close to the onset potential of CdS (Supplementary Fig. 20). The results suggest that the $\mathrm{TiO}_{2} / \mathrm{CdS}$ heterojunction can not only keep the high reduction energy of photogenerated electrons of CdS, but also improve separation efficiency of
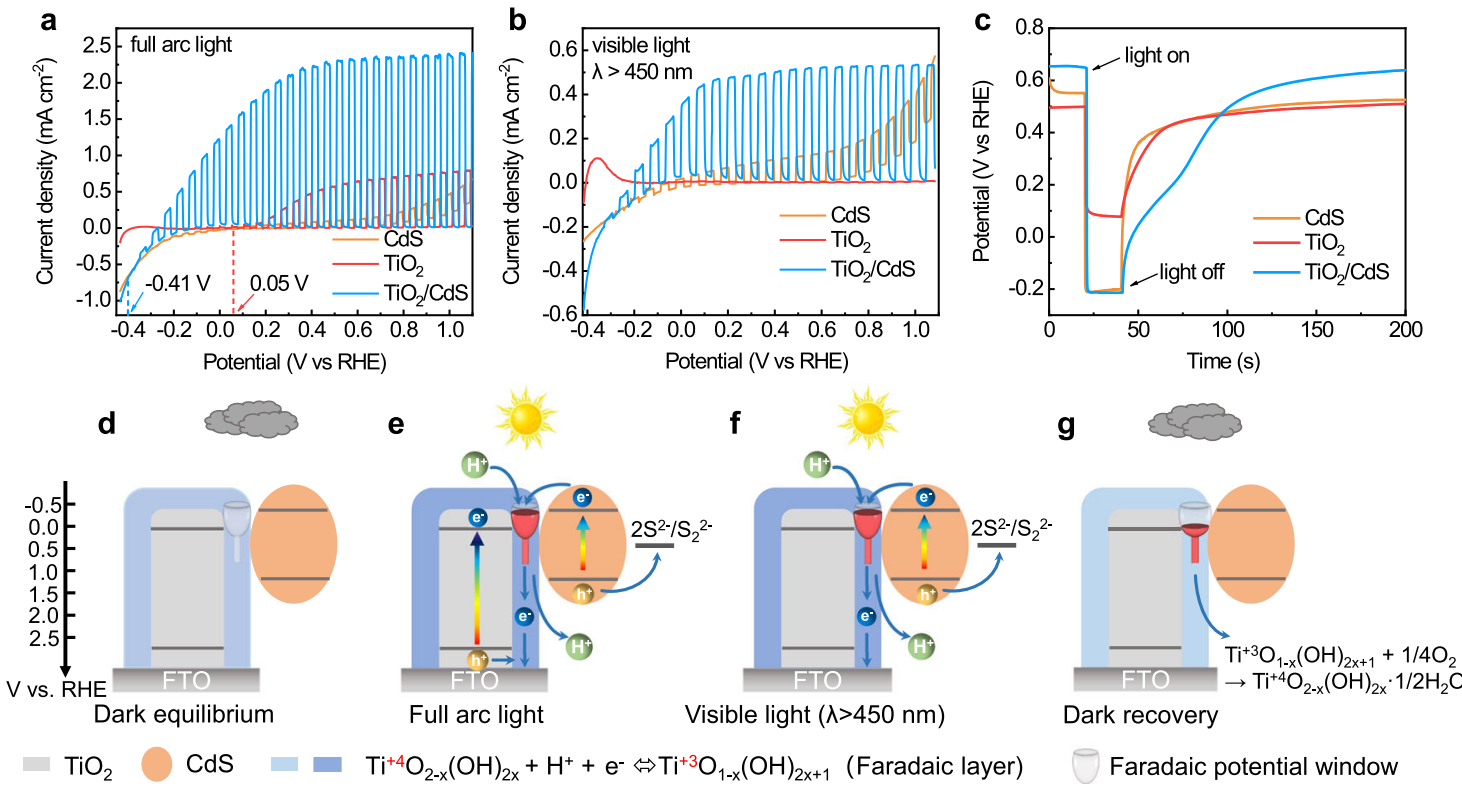

Fig. 4 Characteristic and mechanism of isoenergetic charge transfer in a Faradaic junction. Linear-sweep voltammetry $\mathrm{curves}$ of $\mathrm{TiO}_{2}, \mathrm{CdS}_{\mathrm{S}}$ and $\mathrm{TiO}_{2} /$ $\mathrm{CdS}$ in $1 \mathrm{M} \mathrm{Na}_{2} \mathrm{~S}$ aqueous solution under chopped full-arc Xe lamp illumination without (a) and with (b) a filter (wavelength $>450 \mathrm{~nm}$ ); (c) open-circuit potential of $\mathrm{TiO}_{2}, \mathrm{CdS}$, and $\mathrm{TiO}_{2} / \mathrm{CdS}$ in $1 \mathrm{M} \mathrm{Na}_{2} \mathrm{~S}$ aqueous solution with air in the dark and under illumination; (d-g) interface charge-transfer mechanisms in $\mathrm{TiO}_{2} / \mathrm{CdS}$ heterojunction in the dark and under illumination. 
photogenerated carriers simultaneously. An OCP method was also used to investigate interface charge-transfer process in the $\mathrm{TiO}_{2} / \mathrm{CdS}$ heterojunction (Fig. 4c). $\mathrm{TiO}_{2}, \mathrm{CdS}$, and $\mathrm{TiO}_{2} / \mathrm{CdS}$ indicate different open-circuit potentials in the dark, which comes from chemical equilibrium between a sample surface and redox couples in the electrolyte. Under illumination, open-circuit potentials of the three samples are $0.07 \mathrm{~V}_{\mathrm{RHE}},-0.2 \mathrm{~V}_{\mathrm{RHE}}$, and $-0.2 \mathrm{~V}_{\mathrm{RHE}}$, respectively. The open-circuit potential of $\mathrm{TiO}_{2}$ under illumination is close to its onset potential. However, the opencircuit potential of CdS under illumination is $210 \mathrm{mV}$ positive than its onset potential. The OCP is a potential with zero current, which indicates equilibrium potential of photooxidation for $\mathrm{S}^{2-}$ and dark reduction of $S$ on a sample. There is much higher darkreduction current of $S$ than photooxidation for $S^{2-}$ on $\mathrm{CdS}$ at the potential negative than $-0.2 \mathrm{~V}_{\mathrm{RHE}}$ (Supplementary Fig. 21a), which leads to the OCP of CdS pinning at $-0.2 \mathrm{~V}_{\mathrm{RHE}}$. In contrast, no obvious dark-reduction current of $\mathrm{S}$ is observed on $\mathrm{TiO}_{2}$ (Supplementary Fig. 21b). Therefore, the OCP of CdS under illumination is different from its onset potential, while the OCP of $\mathrm{TiO}_{2}$ under illumination is close to the onset potential. The $\mathrm{TiO}_{2} /$ $\mathrm{CdS}$ indicates the same open-circuit potential under illumination to that of $\mathrm{CdS}$, which further confirms that transferred electrons from CdS to $\mathrm{TiO}_{2}$ indicate the same energy to those in CdS. Moreover, when the light is off, slower decay process of OCP on $\mathrm{TiO}_{2}$ comes from reoxidization of the reduced-surface Faradaic layer by oxygen in the electrolyte (Supplementary Fig. 22). A $\mathrm{TiO}_{2} / \mathrm{CdS}$ heterojunction indicates the slowest decay process of the open-circuit potential among the three samples when the light is off. It is because of much negative potential of the photogenerated electrons in $\mathrm{TiO}_{2} / \mathrm{CdS}$ than that of $\mathrm{TiO}_{2}$, which leads to deeper reduction of the intrinsic Faradaic layer. Therefore, a $\mathrm{TiO}_{2} / \mathrm{CdS}$ heterojunction indicates an unusual isoenergetic interface charge transfer by a Faradaic reaction under illumination.

According to the above results and analysis, we propose an

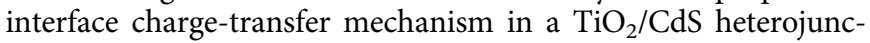
tion in Fig. $4 \mathrm{~d}-\mathrm{g}$. In the dark, there is an intrinsic Faradaic layer of $\mathrm{Ti}^{+4} \mathrm{O}_{2-\mathrm{x}}(\mathrm{OH})_{2 \mathrm{x}}$ at the interface of $\mathrm{T} \mathrm{TiO}_{2} / \mathrm{CdS}$ heterojunction. The composition of the intrinsic Faradaic layer sensitively depends on potential and chemical equilibrium between a sample surface and redox couples in the electrolyte. Under illumination, photogenerated electrons in the conduction band of CdS transfer to $\mathrm{TiO}_{2}$, as well as $\mathrm{H}^{+}$from the electrolyte, which reduce the intrinsic Faradaic layer $\left(\mathrm{Ti}^{+4} \mathrm{O}_{2-\mathrm{x}}(\mathrm{OH})_{2 \mathrm{x}}\right)$ and raise its fermi level to the same position with the conduction-band bottom of CdS. Therefore, isoenergetic interfacial charge transfer is observed in a $\mathrm{TiO}_{2} / \mathrm{CdS}$ junction under illumination. The resistance of the reduced Faradaic layer $\left(\mathrm{Ti}^{+3} \mathrm{O}_{1-\mathrm{x}}(\mathrm{OH})_{2 \mathrm{x}+1}\right)$ decreases remarkably and forms a short-circuit pathway for the electron transfer from the surface of $\mathrm{TiO}_{2}$ to a FTO substrate directly, not through the bulk of $\mathrm{TiO}_{2}$ (Fig. 4e), which is different from type-II heterojunction (Supplementary Fig. 23). Under full arc illumination, both of $\mathrm{TiO}_{2}$ and $\mathrm{CdS}$ are excited, the photogenerated electrons on $\mathrm{TiO}_{2}$ transfer to the FTO substrate through the bulk of $\mathrm{TiO}_{2}$, and the photogenerated holes diffuse to the surface of $\mathrm{TiO}_{2}$ and react with the reduced-surface Faradaic layer of $\mathrm{Ti}$ $+3 \mathrm{O}_{1-\mathrm{x}}(\mathrm{OH})_{2 \mathrm{x}+1}$. Though a Faradaic reaction is observed at $\mathrm{TiO}_{2} / \mathrm{CdS}$ interface, the interface charge-transfer mechanism is also different from that in an indirect Z-scheme heterojunction with $\mathrm{Au}$ or redox shuttle as electron mediator (Supplementary Fig. 24) $)^{36}$. In a Faradaic junction, photogenerated electrons transfer from $\mathrm{CdS}$ to $\mathrm{TiO}_{2}$, however, reverse charge transfer direction in a Z-scheme junction. Under visible-light illumination $(>450 \mathrm{~nm}$ ), only CdS is excited (Fig. $4 \mathrm{f}$ ), the reduced Faradaic layer of $\mathrm{Ti}^{+3} \mathrm{O}_{1-\mathrm{x}}(\mathrm{OH})_{2 \mathrm{x}+1}$ plays a role as a charge separator by a fast Faradaic reaction and an electron-transfer pathway, which can improve the photoelectrochemical performance of CdS. When the light is off, the reduced Faradaic layer can be oxidized by oxygen in the electrolyte and a reversible Faradaic reaction happens, which leads to the Fermi level recovering to the initial value before illumination (Fig. $4 \mathrm{~g}$ ). Therefore, the interface charge-transfer mechanism in a $\mathrm{TiO}_{2} / \mathrm{CdS}$ heterojunction is neither type-II heterojunction nor Z-scheme heterojunction, but a Faradaic junction, in which the characteristic of zero-energy loss and high charge-separation efficiency can be obtained at the same time by a fast and reversible Faradaic reaction.

In order to further investigate universality of the semiconductor/ semiconductor Faradaic junction theory, we also prepared different oxide semiconductors $\left(\mathrm{ZnO}, \mathrm{Nb}_{2} \mathrm{O}_{5}\right.$, and $\left.\mathrm{Fe}_{2} \mathrm{O}_{3}\right)$ to replace $\mathrm{TiO}_{2}$ and constructed heterojunctions with $\mathrm{CdS}$ (Supplementary Figs. 26 and 27). Similar to $\mathrm{TiO}_{2} / \mathrm{CdS}$, impedance semicircles of the $\mathrm{ZnO} / \mathrm{CdS}$, $\mathrm{Nb}_{2} \mathrm{O}_{5} / \mathrm{CdS}$, and $\mathrm{Fe}_{2} \mathrm{O}_{3} / \mathrm{CdS}$ decrease after illumination, which also possibly come from reduction of intrinsic Faradaic layers of $\mathrm{ZnO}$, $\mathrm{Nb}_{2} \mathrm{O}_{5}$ and $\mathrm{Fe}_{2} \mathrm{O}_{3}$ by photogenerated electrons from CdS (Supplementary Fig. 28). Moreover, $\mathrm{ZnO} / \mathrm{CdS}$ and $\mathrm{Nb}_{2} \mathrm{O}_{5} / \mathrm{CdS}$ heterojunctions indicate close onset potentials to that of CdS. However, the onset potential of $\mathrm{Fe}_{2} \mathrm{O}_{3} / \mathrm{CdS}$ heterojunction indicates $0.56 \mathrm{~V}$ positive than that of CdS (Supplementary Figs. 29-30). These results suggest that isoenergetic charge transfer also happens at $\mathrm{ZnO} / \mathrm{CdS}$ and $\mathrm{Nb}_{2} \mathrm{O}_{5} / \mathrm{CdS}$ interfaces, but not at $\mathrm{Fe}_{2} \mathrm{O}_{3} / \mathrm{CdS}$ interface. In order to explain this phenomenon, we measured the Faradaic potential windows of $\mathrm{ZnO}, \mathrm{Nb}_{2} \mathrm{O}_{5}$, and $\mathrm{Fe}_{2} \mathrm{O}_{3}$ and the results are plotted in Supplementary Fig. 31. $\mathrm{ZnO}$ and $\mathrm{Nb}_{2} \mathrm{O}_{5}$ indicate similar Faradaic potential windows to that of $\mathrm{TiO}_{2}$, while the Faradaic potential window of $\mathrm{Fe}_{2} \mathrm{O}_{3}$ is $0.50 \mathrm{~V}$ positive than that of $\mathrm{TiO}_{2}$. When a potential negative than $0.03 \mathrm{~V}_{\mathrm{RHE}}$ is applied on a $\mathrm{Fe}_{2} \mathrm{O}_{3}$ electrode, a corrosion reaction $\left(\mathrm{Fe}^{+3} \mathrm{O}_{\mathrm{x}}(\mathrm{OH})_{3-2 \mathrm{x}}+3 \mathrm{H}^{+}\right.$ $\left.+\mathrm{e}^{-} \rightarrow \mathrm{Fe}^{2+}+(3-\mathrm{x}) \mathrm{H}_{2} \mathrm{O}\right)$ happens and $\mathrm{Fe}_{2} \mathrm{O}_{3}$ is dissolved into the electrolyte (Supplementary Fig. 32). Therefore, when the photogenerated electrons in the conduction band of CdS transfer to $\mathrm{ZnO}$ and $\mathrm{Nb}_{2} \mathrm{O}_{5}$, the intrinsic Faradaic layers can be charged and their fermi levels can be raised to the same position with the conduction-band bottom of CdS. The results can explain the $\mathrm{V}_{\mathrm{OC}}$ dependent on a quantum-dot sensitizer but not on an electrontransporting material in quantum-dot-sensitized or perovskite solar cells ${ }^{10-12}$. However, when the photogenerated electrons in the conduction band of $\mathrm{CdS}$ transfer to $\mathrm{Fe}_{2} \mathrm{O}_{3}$, the photogenerated electrons will lead to dissolution of $\mathrm{Fe}_{2} \mathrm{O}_{3}$. Therefore, a prerequisite of isoenergetic charge transfer at semiconductor/semiconductor Faradaic interfaces is that the conduction-band position of an electrondonor semiconductor should overlap with a Faradaic potential window of an electron-acceptor semiconductor (Supplementary Fig. 33).

\section{Discussion}

In summary, we propose a Faradaic junction mechanism on a $\mathrm{TiO}_{2} / \mathrm{CdS}$ heterojunction, which is substantively different from classic band-alignment theory on a semiconductor/semiconductor junction. The Faradaic junction mechanism is observed not only in liquid-phase, but also in gas-phase and solid-phase surroundings. Moreover, we find that a $\mathrm{TiO}_{2} / \mathrm{CdS}$ Faradaic junction indicates unusual isoenergetic interface charge transfer, which can be used to explain abnormal photovoltages or reduction/oxidation potential in quantum dot/perovskite solar cells and photo(electro)catalysis. We also propose a prerequisite of isoenergetic charge transfer in semiconductor/semiconductor Faradaic junctions. The Faradaic junction theory can offer a different perspective to design semiconductors with suitable Faradaic potential windows, but not conventional band positions, for high-performance solar energy conversion and storage. 


\section{Methods}

Preparation of $\mathrm{TiO}_{\mathbf{2}}$ nanorod films. $\mathrm{TiO}_{2}$ nanorod films were prepared on FTO substrates by hydrothermal method ${ }^{25}$. Briefly, $15 \mathrm{~mL}$ of deionized water and $15 \mathrm{~mL}$ of $\mathrm{HCl}$ were mixed and stirred for $10 \mathrm{~min}$. Then, $0.45 \mathrm{~mL}$ of titanium butoxide was added. The solution was transferred to a Teflon-lined steel autoclave with inserting FTO substrates in it. The hydrothermal reaction was conducted at $150^{\circ} \mathrm{C}$ for $9 \mathrm{~h}$. Finally, the deposited films were washed by deionized water and calcined at $450^{\circ} \mathrm{C}$ for $1 \mathrm{~h}$ in air.

Preparation of $\mathrm{CdS}$ on $\mathrm{TiO}_{2}$ nanorod array by SILAR method. CdS QDs were grown on the $\mathrm{TiO}_{2}$ nanorod array by successive ionic-layer adsorption and reaction (SILAR) method ${ }^{37,38}$. Typically, the $\mathrm{TiO}_{2}$ nanorod array films were immersed in $\mathrm{Cd}\left(\mathrm{CH}_{3} \mathrm{COO}\right)_{2}$ solution $(0.1 \mathrm{M})$ for $2 \mathrm{~min}$ and rinsed with deionized water, and then immersed in $\mathrm{Na}_{2} \mathrm{~S}$ solution $(0.1 \mathrm{M})$ for another 2 min followed by another rinsing with deionized water. Such a SILAR cycle was repeated for 15 times to obtain $\mathrm{TiO}_{2} / \mathrm{CdS}$ samples. CdS on FTO substrates was also prepared by the same method as reference samples.

Characterization of samples. X-ray diffraction (XRD smartlab $9 \mathrm{~kW}$ ) was used to characterize the crystal structures of the samples. Scanning electron microscope (SEM Nano Nova S230) and transmission electron microscope (TEM Tecnai G2 F20) were used to investigate the morphologies of the samples. X-ray photoelectron spectroscopy (XPS) was performed on a K-Alpha instrument operating with an $\mathrm{Al}$ $\mathrm{Ka} \mathrm{X}$-ray source. The binding energy was calibrated by C1s peak at $284.6 \mathrm{eV}$. Photoluminescence spectra (PL) of the samples were collected by a Renishaw InVia Raman Micro-PL system with a 375-nm He-Cd laser. Time-of-flight secondaryion mass spectrometry (TOF-SIMS 5 iontof, PHI NanoTOFII) was used to analyze depth profiles of ions in the Faradaic junction before and after illumination.

In situ characterization of samples. In situ UV-vis reflection spectra (UV, Shimadzu UV-2550) and in situ Raman (Horiba T64000, excitation wavelength $\sim 488 \mathrm{~nm}$ ) in the dark were measured in a cell with a Pt wire and a saturated $\mathrm{Ag} /$ $\mathrm{AgCl}$ electrode as the counter and reference electrode, respectively. The electrolyte was $1 \mathrm{M} \mathrm{Na}_{2} \mathrm{~S}$ aqueous solution $(\mathrm{pH}$ 13.3). An electrochemical analyzer $(\mathrm{CHI}$ 760 e, Shanghai Chenhua) was used to control the potentials of the samples. Quasi in situ UV-vis reflection and Raman spectra were measured immediately after the photoelectrodes were illuminated by a Xe lamp in $1 \mathrm{M} \mathrm{Na} \mathrm{Na}_{2} \mathrm{~S}$ aqueous solution $(\mathrm{pH} 13.3)$ at an open-circuit potential.

In situ X-ray photoelectron spectroscopy (Thermofisher Escalab 250Xi) was performed under a full-arc Xe lamp. The prepared $\mathrm{TiO}_{2} / \mathrm{CdS}$ sample was kept in the dark before the test. The sample was immersed in $0.5 \mathrm{M} \mathrm{Na}_{2} \mathrm{SO}_{3}$ aqueous solution and dried in air. Before measurement, the sample was exposed to water vapor for $10 \mathrm{~min}$, and then in situ XPS was measured on the sample in the dark and after 3-mins' illumination.

Photoelectrochemical measurement. The photoelectrochemical properties of the films were investigated in a three-electrode cell using an electrochemical analyzer (CHI 760e, Shanghai Chenhua) under a Xe lamp with an AM 1.5 sunlightsimulator filter illumination (light intensity: $100 \mathrm{~mW} / \mathrm{cm} 2$ ). A Pt mesh and a saturated $\mathrm{Ag} / \mathrm{AgCl}$ electrode were used as a counter electrode and a reference electrode, respectively. The electrolyte was $1 \mathrm{M} \mathrm{Na}_{2} \mathrm{~S}$ aqueous solution ( $\mathrm{pH}$ 13.3). A reversible hydrogen electrode (RHE) potential was obtained by the following formula: $\mathrm{V}_{\mathrm{RHE}}=\mathrm{V}_{\mathrm{Ag} / \mathrm{AgCl}}+0.059 * \mathrm{pH}+0.197$. The quantum-dot-sensitized solar cell full device was assembled by using $\mathrm{TiO}_{2} / \mathrm{CdS}$ as a photoelectrode and a Ptsputtered FTO as a counter electrode. The electrolyte was $0.5 \mathrm{M} \mathrm{Na}_{2} \mathrm{~S}, 2 \mathrm{MS}$, and $0.2 \mathrm{M} \mathrm{KCl}$ in water/methanol (3:7 by volume $)^{39}$. The I-V curves of solid-state solar cells were measured by Keithley 2450 .

Reporting summary. Further information on research design is available in the Nature Research Reporting Summary linked to this article.

\section{Data availability}

The data that support the findings of this study are available from the corresponding authors upon reasonable request.

Received: 28 June 2021; Accepted: 14 October 2021;

Published online: 04 November 2021

\section{References}

1. Shockley, W. The theory of $p$ - $n$ junctions in semiconductors and $p-n$ junction transistors. Bell Syst. Tech. J. 28, 435-489 (1949).

2. Chapin, D. M., Fuller, C. S. \& Pearson, G. L. A new silicon p-n junction photocell for converting solar radiation into electrical power. J. Appl. Phys. 25, 676-677 (1954).
3. Shockley, W. \& Queisser, H. J. Detailed balance limit of efficiency of $p-n$ junction solar cells. J. Appl. Phys. 32, 510-519 (1961).

4. Semonin, O. E. et al. Peak external photocurrent quantum efficiency exceeding $100 \%$ via MEG in a quantum dot solar cell. Science 334, 1530-1533 (2011).

5. Tvrdy, K., Frantsuzov, P. A. \& Kamat, P. V. Photoinduced electron transfer from semiconductor quantum dots to metal oxide nanoparticles. Proc. Natl Acad. Sci. USA 108, 29-34 (2011).

6. McDaniel, H., Fuke, N., Makarov, N. S., Pietryga, J. M. \& Klimov, V. I. An integrated approach to realizing high-performance liquid-junction quantum dot sensitized solar cells. Nat. Commun. 4, 2887 (2013).

7. Kojima, A., Teshima, K., Shirai, Y. \& Miyasaka, T. Organometal halide perovskites as visible-light sensitizers for photovoltaic cells. J. Am. Chem. Soc. 131, 6050-6051 (2009).

8. Shi, E. et al. Two-dimensional halide perovskite lateral epitaxial heterostructures. Nature 580, 614-620 (2020).

9. Li, Z. et al. Extrinsic ion migration in perovskite solar cells. Energy Environ. Sci. 10, 1234-1242 (2017)

10. Jena, A. K., Kulkarni, A. \& Miyasaka, T. Halide perovskite photovoltaics: background, status, and future prospects. Chem. Rev. 119, 3036-3103 (2019).

11. Du, J. et al. Zn-Cu-In-Se quantum dot solar cells with a certified power conversion efficiency of 11.6\%. J. Am. Chem. Soc. 138, 4201-4209 (2016)

12. Li, T.-L., Lee, Y.-L. \& Teng, H. High-performance quantum dot-sensitized solar cells based on sensitization with $\mathrm{CuInS}_{2}$ quantum dots/CdS heterostructure. Energy Env. Sci. 5, 5315-5324 (2012).

13. Wang, X. et al. Enhanced photocatalytic hydrogen evolution by prolonging the lifetime of carriers in $\mathrm{ZnO} / \mathrm{CdS}$ heterostructures. Chem. Commun. 10.1039/ b904668b (2009).

14. Sasaki, Y., Nemoto, H., Saito, K. \& Kudo, A. Solar water splitting using powdered photocatalysts driven by Z-schematic interparticle electron transfer without an electron mediator. J. Phys. Chem. C 113, 17536-17542 (2009).

15. Kosco, J. et al. Enhanced photocatalytic hydrogen evolution from organic semiconductor heterojunction nanoparticles. Nat. Mater. 19, 559-565 (2020).

16. Zhao, D. et al. Boron-doped nitrogen-deficient carbon nitride-based Z-scheme heterostructures for photocatalytic overall water splitting. Nat. Energy 6, 388-397 (2021)

17. Low, J., Yu, J., Jaroniec, M., Wageh, S. \& Al-Ghamdi, A. A. Heterojunction photocatalysts. Adv. Mater. 29, 1601694 (2017).

18. Tomkiewicz, M. \& Woodall, J. M. Photoelectrolysis of water with semiconductor materials. J. Electrochem. Soc. 124, 1436-1440 (1977).

19. Hong, S. J., Lee, S., Jang, J. S. \& Lee, J. S. Heterojunction $\mathrm{BiVO}_{4} / \mathrm{WO}_{3}$ electrodes for enhanced photoactivity of water oxidation. Energy Environ. Sci. 4, 1781 (2011).

20. Xie, M. et al. Long-lived, visible-light-excited charge carriers of $\mathrm{TiO}_{2} / \mathrm{BiVO}_{4}$ nanocomposites and their unexpected photoactivity for water splitting. Adv. Energy Mater. 4, 1300995 (2014).

21. Xu, Q. et al. Direct Z-scheme photocatalysts: Principles, synthesis, and applications. Mater. Today 21, 1042-1063 (2018).

22. Gong, Y. et al. All-solid-state Z-scheme $\mathrm{CdTe} / \mathrm{TiO}_{2}$ heterostructure photocatalysts with enhanced visible-light photocatalytic degradation of antibiotic waste water. Chem. Eng. J. 350, 257-267 (2018).

23. Chen, $X$. et al. Reversible charge transfer and adjustable potential window in semiconductor/Faradaic layer/liquid junctions. iScience 23, 100949 (2020).

24. Wang, P. et al. A capacitor-type Faradaic junction for direct solar energy conversion and storage. Angew. Chem. Int. Ed. 60, 1390-1395 (2021).

25. Yin, Z. et al. Mildly regulated intrinsic faradaic layer at the oxide/water interface for improved photoelectrochemical performance. Chem. Sci. 11, 6297-6304 (2020)

26. Ishikawa, A. et al. Oxysulfide $\mathrm{Sm}_{2} \mathrm{Ti}_{2} \mathrm{~S}_{2} \mathrm{O}_{5}$ as a stable photocatalyst for water oxidation and reduction under visible light irradiation $(\lambda \leq 650 \mathrm{~nm})$. J. Am. Chem. Soc. 124, 13547-13553 (2002).

27. Fleming, L. et al. Local bonding analysis of the valence and conduction band features of $\mathrm{TiO}_{2}$. J. Appl. Phys. 102, 033707 (2007).

28. Wang, S. et al. Direct Z-scheme $\mathrm{ZnO} / \mathrm{CdS}$ hierarchical photocatalyst for enhanced photocatalytic $\mathrm{H}_{2}$-production activity. Appl. Catal. B Environ. 243, 19-26 (2019).

29. Santra, P. K. \& Kamat, P. V. Tandem-layered quantum dot solar cells: tuning the photovoltaic response with luminescent ternary cadmium chalcogenides. $J$. Am. Chem. Soc. 135, 877-885 (2013).

30. $\mathrm{Xu}, \mathrm{X}$. et al. Dynamics of bound exciton complexes in CdS nanobelts. ACS Nano 5, 3660-3669 (2011).

31. Kim, Y.-S. et al. Evidencing fast, massive, and reversible $\mathrm{H}^{+}$insertion in nanostructured $\mathrm{TiO}_{2}$ electrodes at neutral $\mathrm{pH}$. Where do protons come from? J. Phys. Chem. C 121, 10325-10335 (2017).

32. Feldblum, A. et al. Opto-electrochemical spectroscopy of trans $-(\mathrm{CH})_{\mathrm{x}}$. Phys Rev. B 26, 815-826 (1982).

33. $\mathrm{Wu}, \mathrm{X}$. L. et al. Green light stimulates terahertz emission from mesocrystal microspheres. Nat. Nanotechnol. 6, 103-106 (2011). 
34. Lu, Y. et al. Self-hydrogenated shell promoting photocatalytic $\mathrm{H}_{2}$ evolution on anatase $\mathrm{TiO}_{2}$. Nat. Commun. 9, 2752 (2018).

35. Fabregat-Santiago, F. et al. High carrier density and capacitance in $\mathrm{TiO}_{2}$ nanotube arrays induced by electrochemical doping. J. Am. Chem. Soc. 130 11312-11316 (2008).

36. Tada, H., Mitsui, T., Kiyonaga, T., Akita, T. \& Tanaka, K. All-solid-state Z-scheme in CdS-Au- $\mathrm{TiO}_{2}$ three-component nanojunction system. Nat. Mater. 5, 782-786 (2006).

37. Wang, $\mathrm{H}$. et al. CdS quantum dots-sensitized $\mathrm{TiO}_{2}$ nanorod array on transparent conductive glass photoelectrodes. J. Phys. Chem. C 114, 16451-16455 (2010).

38. Zhou, R. et al. Influence of cationic precursors on CdS quantum-dotsensitized solar cell prepared by successive ionic layer adsorption and reaction. J. Phys. Chem. C 117, 26948-26956 (2013).

39. Lee, Y.-L. \& Chang, C.-H. Efficient polysulfide electrolyte for CdS quantum dot-sensitized solar cells. J. Power Sources 185, 584-588 (2008)

\section{Acknowledgements}

The authors thank Dr. Sheng Chu at Southeast University and Prof. Yupeng Yuan at Anhui University for their helpful suggestion, and thank Mr. Xiaopeng Han and Mr. Zhi Zhu for the fabrication of gold electrodes. This work was supported by the National Key R\&D Program of China (2017YFE0120700, 2018YFE0208500), the National Natural Science Foundation of China $(21875105,51972164)$, the National Scientific Instrument Develop Major Project of National Natural Science Foundation of China (51627810), and Foshan Xianhu Laboratory of the Advanced Energy Science and Technology Guangdong Laboratory (XHD2020-002).

\section{Author contributions}

W.L. supervised the project, proposed the concept and designed the experiments. M.C. carried out sample preparation and electrochemical measurements; M.C., H.D. and M.X. carried out the characterization; W.L. and M.C. analyzed the data and wrote the paper. C.Y., P.W., Y.Y., H.Z., C.W., Y.Y. and Z.Z. discussed the results and gave comments on the paper.

\section{Competing interests}

The authors declare no competing interests.

\section{Additional information}

Supplementary information The online version contains supplementary material available at https://doi.org/10.1038/s41467-021-26661-6.

Correspondence and requests for materials should be addressed to Wenjun Luo.

Peer review information Nature Communications thanks Wingkei Ho and the other, anonymous, reviewer(s) for their contribution to the peer review of this work.

Reprints and permission information is available at http://www.nature.com/reprints

Publisher's note Springer Nature remains neutral with regard to jurisdictional claims in published maps and institutional affiliations.

(c) Open Access This article is licensed under a Creative Commons Attribution 4.0 International License, which permits use, sharing, adaptation, distribution and reproduction in any medium or format, as long as you give appropriate credit to the original author(s) and the source, provide a link to the Creative Commons license, and indicate if changes were made. The images or other third party material in this article are included in the article's Creative Commons license, unless indicated otherwise in a credit line to the material. If material is not included in the article's Creative Commons license and your intended use is not permitted by statutory regulation or exceeds the permitted use, you will need to obtain permission directly from the copyright holder. To view a copy of this license, visit http://creativecommons.org/ licenses/by/4.0/.

(C) The Author(s) 2021 